\title{
Reaching a tipping point
}

\section{A popular new paradigm for the nature of change pertains more to the social and political worlds than it does to the physical one.}

$\mathrm{R}$ arely since Catch 22 has a book title made its mark on the language in such a way as The Tipping Point. The author, Malcolm Gladwell, made no claim to have invented the term, but his thought-provoking book brought the idea into common parlance. Since then, the view that incremental changes in a cause can suddenly produce a much larger effect has entered common currency. It is now being ever more frequently deployed in the debate about the world's climate.

In some respects, this is old wine in new bottles. For almost as long as people have been worrying about anthropogenic climate change, there have been warnings that, although the build-up of greenhouse gases may be slow and gradual, the effects they will have on the system need not be. The physical, chemical and biological responses that turn greenhouse gases into climate change are complex and subtle, and capable of responses that are surprisingly disproportionate. There are thresholds beyond which the past response of the system no longer predicts the future, and there are positive feedbacks through which change can feed on itself. All these possibilities are now being discussed under the rubric of tipping points.

It is reasonable to worry about such things, but there are three dangers attendant on focusing humanity's response to the climate crisis too much on tipping points. The first is the uncertainty of the science; the second is the tendency of such an emphasis to distort our responses; the third is the danger of fatalism.

The models through which our understanding of the climate system are channelled into assessments of how it might behave in the future are impressive by the standards of human investigation, but crude with respect to the details of the Earth system. All sorts of phenomena, from the formation of clouds to the respiration of soils, are hard to capture accurately, and it is on such details that an understanding of possible tipping points depends (see page 802). Anyone claiming to know for sure when a particular tipping point will be reached should be treated with suspicion - and so must anyone who suggests that no tipping point will ever be reached.

The second problem is that an emphasis on tipping points not yet reached increases the focus on the future. Such an increase tips the balance away from adapting to climate change and in favour of trying to avoid it. A rational response to the challenge of the twenty-first century's climate is to do both: to reduce the rate at which greenhouse gases force climate change, but at the same time build up the ability to cope with adverse climates.

The third issue is that tipping points can induce fatalism. The concept may encourage the belief that a complete solution is the only worthwhile one, as any other course may allow the climate system to tumble past the crucial threshold. This sort of allor-nothing approach is already over-stressed in climate policy by the Framework Convention
"Anyone claiming to know for sure when a particular tipping point will be reached should be treated with suspicion." on Climate Change, which calls for the complete avoidance of dangerous anthropogenic climate change, rather than the more reasonable and more feasible goal of minimizing and controlling it.

The concept of the tipping point is, in fact, more pertinent to the climate crisis in the social sphere than in the physical world. The strength of Gladwell's book lies in its reasoned illustrations of the ways in which beliefs and behaviours change, and the rules and contexts that govern that change. It is possible to make people change their minds and behaviours, and for those changes to spread like a contagion. "Look at the world around you," Gladwell argues. "It may seem like an immovable, implacable place. It is not. With the slightest push — in just the right place — it can be tipped."

\section{A fresh start}

\section{Will a change of management at Los Alamos put basic research under pressure?}

E L arlier this month, with mercifully little fanfare, scientists at Los Alamos National Laboratory in New Mexico witnessed a changing of the guard. For 63 years, the world's best-known nuclear-weapons laboratory had been under the management of the University of California. From 1 June, the university will run it in partnership with three commercial companies.

With luck, the change will conclude a period of turbulence at the laboratory, which began when Taiwanese-born scientist Wen Ho Lee was suspected of espionage in 1999 (see Nature 398, 96; 1999). Lee was never charged, and in the end pleaded guilty to mishandling classified data, but the lab has since been plagued by a series of security and procurement scandals. That encouraged the Department of Energy, which oversees the facility, to open its management contract up to bidding for the first time (see Nature 423, 104; 2003).

Under a contract that runs until 2013, the university will run the laboratory jointly with San Francisco-based Bechtel National, an engineering contractor that already manages several US nuclear weapons facilities. Two other companies, BWX Technologies and Washington Group International, will also play roles in managing the laboratory's nuclear equipment and its hazardous waste.

The energy department and its congressional overseers hope the new arrangement will bring best business practice to the laboratory and draw its recent difficulties to a close. The laboratory's staff, who will retain their pension rights and status within the University of 
California, are also hoping that the change will quell public criticism of the laboratory.

But for scientists at the lab, this hope is tinged with concern that the new management will shift its focus away from basic research. Both BWX Technologies and Bechtel have a track record in engineering management, overseeing production facilities for US nuclear weapons. They are for-profit institutions, more interested in meeting government schedules than nurturing scientific excellence.

There are still grounds for optimism that science won't take a back seat at Los Alamos. The lab's new director, Michael Anastasio, is a physicist with a distinguished career in nuclear-weapons design. Other Department of Energy facilities under joint business and university management, such as Oak Ridge National Laboratory in Tennessee, have continued to do good science.

None of these places enjoy Los Alamos's intellectual reputation, however, and fears persist of a shift in priorities at the New Mexico laboratory. The energy department is considering the construction of a multi-billion-dollar facility there to produce replacement plutonium triggers for existing nuclear weapons. In the zero-sum game

that is the Department of Energy's budget process, scientists fear that a larger weapons-production role at Los Alamos will come at the expense of its research programmes - especially those not directly related to nuclear weapons.

The main strength of Los Alamos has always been its ability to attract good people by offering exceptional facilities dedicated to a range of scientific enquiry. It is home to some of the world's most powerful supercomputers, which are used for such purposes as simulating a possible bird-flu epidemic. The laboratory also houses acknowledged

"Scientists fear that a larger weapons-production role at Los Alamos will come at the expense of its research programmes." global leaders in neutron science, mathematics, computer science, nuclear non-proliferation, and more. The scientists and engineers who work on nuclear weapons there rely on the non-weapons work to retain links with the wider academic world. That interface is what makes Los Alamos special, and the laboratory's fresh management team should nurture it with care.

\section{Cash-per-publication...}

.....is an idea best avoided.

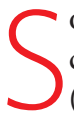
outh Korea has become the latest country to offer scientists cash prizes for publications in top-level international journals (see age 792). Other nations, including China and Pakistan, already have such programmes in place. The thousands, or even tens of thousands, of dollars on offer can be a fat prize for researchers in countries with lean science budgets.

Many researchers will turn up their noses at this practice. Scientists, after all, are supposed to be motivated by curiosity, by a devotion to finding the truth, by a desire to solve various philosophical or social problems - not by money. And funds should find their way to self-motivated scientists with a project deemed important. This assessment should be made by taking account of the project's feasibility, originality and scientific significance.

But this is no easy task in any country. In countries with inexperienced or understaffed scientific evaluation committees, it is almost impossible. Without the proper mechanism in place, funding can be diluted by equal distribution to all, or hijacked by projects approved on the basis of personal connections rather than sound science. Where there is little faith in review committees, giving money directly to those who have proven themselves might seem a beneficial, albeit imperfect, way of encouraging scientists.

Proponents can point to other potential advantages too. Scaling up bonuses for high-impact papers, as these programmes often do, might stem the urge to churn out quick papers in order to beef up a publication list. (Graduate students in China often need to have several publications for higher degrees.) And they also encourage scientists in countries with traditions of local-language publishing to think more internationally.

But there are some powerful arguments against the widespread adoption of the practice. Cash bonuses tied to specific publications are likely to exacerbate corrupting tendencies in the scientific community. Debates over who should be included on author lists, and who should be the first author and the corresponding author, will surely get even more vicious when a chunk of money is on the line. A scientist struggling to meet a mortgage payment might be more willing to forgo a potentially fantastic result for a quick cash-earner. And a researcher measuring science in terms of dollars might even be more tempted to plagiarize or fabricate data.

In countries recently damaged by high-profile cases of scientific corruption, where it is all the more essential to develop a culture of integrity, the award of large sums of money for high-impact publications is even less desirable. The scientific world already places too much importance on high-impact journals in assessing individuals, and on the crude 'impact factor' in particular (see Nature 435, 1003-1004; 2005). Papers published in journals with high impact factors do indeed tend to be significant papers, but a literal formula highly geared in their favour cannot do justice to the way science works.

Money does matter, of course. Scientifically developing countries need to compete for excellent scientists in an increasingly global marketplace. And scientists everywhere use their reputations, based on their latest and greatest papers, to negotiate raises, promotions or new jobs. So countries struggling to find ways of motivating their scientists need to reward outstanding researchers for good publications, perhaps by paying a bonus based on a peer review of achievements over at least a year.

But nations and agencies should avoid resorting to crude cash-perpaper incentives. They should instead attempt to be less formulaic and more considered in the ways they reward their scientists. And they should redouble their efforts to ensure that, in the midst of concerns about rewards, young scientists are committed above all to the ethical pursuit of scientific truths. 